\title{
A Chance-Constrained Vehicle Routing Problem for Wet Waste Collection and Transportation Considering Carbon Emissions
}

\author{
Hailin Wu ${ }^{1}$, Fengming Tao ${ }^{2, *}$, Qingqing Qiao ${ }^{1}$ and Mengjun Zhang ${ }^{1}$ \\ 1 College of Mechanical Engineering, Chongqing University, Chongqing 400044, China; \\ wu_hailin@foxmail.com (H.W.); qiaoqingqing@cqu.edu.cn (Q.Q.); zhangmengjun@cqu.edu.cn (M.Z.) \\ 2 School of Management Science and Real Estate, Chongqing University, Chongqing 400044, China \\ * Correspondence: taofengming@cqu.edu.cn; Tel.: +86-185-8070-7012
}

Received: 15 December 2019; Accepted: 7 January 2020; Published: 10 January 2020

\begin{abstract}
In order to solve the optimization problem of wet waste collection and transportation in Chinese cities, this paper constructs a chance-constrained low-carbon vehicle routing problem (CCLCVRP) model in waste management system and applies certain algorithms to solve the model. Considering the environmental protection point of view, the CCLCVRP model combines carbon emission costs with traditional waste management costs under the scenario of application of smart bins. Taking into the uncertainty of the waste generation rate, chance-constrained programming is applied to transform the uncertain model to a certain one. The initial optimal solution of this model is obtained by a proposed hybrid algorithm, that is, particle swarm optimization (PSO); and then the further optimized solution is obtained by simulated annealing (SA) algorithm, due to its global optimization capability. The effectiveness of PSOSA algorithm is verified by the classic database in a capacitated vehicle routing problem (CVRP). What's more, a case of waste collection and transportation is applied in the model for acquiring reliable conclusions, and the application of the model is tested by setting different waste fill levels (WFLs) and credibility levels. The results show that total costs rise with the increase of credibility level reflecting dispatcher's risk preference; the WFL value range between 0.65 and 0.75 can obtain the optimal solution under different credibility levels. Finally, according to these results, some constructive proposals are propounded for the government and the logistics organization dealing with waste collection and transportation.
\end{abstract}

Keywords: wet waste collection and transportation; chance-constrained programming; carbon emissions; smart waste bins

\section{Introduction}

Solid waste management (SWM) has always been the most concerned issue in every region [1,2] which is composed of many stages including generation, collection and transportation, treatment and disposal $[3,4]$. The process of collection and transportation is one of the most challenging steps among all aspects of SWM [5]. Specially in developing countries, up to 80-90\% of municipal budgets is reserved for waste collection and transportation services [6] which is identified as the most expensive functional element in SWM [1], while the frequency and efficiency are still very low [6]. Therefore, waste collection route optimization is the principal component for achieving the best savings in SWM [7]. In this paper, we consider the collection and transportation of wet waste (defined as biodegradable waste [8]), a kind of solid waste, which is placed in specific waste bins in or around residential areas, then collected and transported to the disposal center by special waste trucks.

Road transportation is the most common mode used for wet waste transportation, during which fuel is consumed and carbon dioxide equivalent emissions are produced. With the emergence of 
environmental pollution problems, the issue of carbon emissions has attracted much attention $[9,10]$. What is more, vehicles produce emissions not only when driving, but also when loading and unloading waste due to the necessity to keep their engines running, producing constant exhaust emissions [11,12]. These considerations highlight the importance of optimizing vehicle routing to reduce the carbon emissions during the process of waste collection and transportation [13].

At present, most research on waste collection is carried out considering fixed routes and collection of all the waste bins according to a predetermined schedule, but this method is not particularly good. In particular, the use of fixed routes might lead to half-full waste bins, overflowing waste bins and high fuel consumption, which are very serious problems [9]. For these reasons, many cities and regions are starting to use smart waste bins to reduce operating costs and improve residents' satisfaction through real-time monitoring of waste volumes. Generally, a smart waste bin is a kind of waste collector which is equipped with different technical devices, such as different sensors systems and RFID to monitor the waste level of bin and achieve the communication between smart waste bins and trucks $[5,14,15]$, accordingly allowing the implementation of real-time optimized transportation routes instead of fixed routes [13].

In short, it is necessary to study both of the wet waste generation rate and carbon emissions in the process of wet waste collection and transportation. Therefore, we must consider the following questions: How to plan the vehicle routes under the scenario of application of smart waste bins; how to handle the stochastic variable of waste generation rate; how to quantify the carbon emissions of waste collection vehicles; and how to build a comprehensive optimization model that considers costs and carbon emissions. Thus, this paper is organized as follows: a literature review of related work is presented in Section 2. The model formulation is proposed in Section 3. The proposed algorithm is described in Section 4. The algorithm experiment and model experiment are shown in Section 5. Finally, conclusions are presented in Section 6.

\section{Literature Review}

The main idea of this article is about waste collection and transportation considering the waste generation rate which will be handled by chance-constrained programming against the background of smart waste bins' application. In the model, the carbon emissions are also considered. We review the literature in three areas: waste collection and transportation (vehicle routing problems, carbon emissions and smart waste bins), chance-constrained programming, and heuristic algorithms.

\subsection{Research about Waste Collection and Transportation}

There is a series of studies about waste collection and transportation including all kinds of waste. Kim et al. [16] established a VRPTW model for commercial waste collection, taking into account multiple waste treatments and driver rest time. Zsigraiova et al. [12] established a vehicle route optimization model for glass waste collection based on a GIS system. Asefi et al. [17] considered different types of waste carried by different vehicles, established a vehicle routing model with the lowest total cost and workload balance of different transfer stations. Markov et al. [18] established a recyclable waste collection routes optimization problem considering random inventory and established a waste prediction model based on sensor data and historical data of the waste collection container.

A range of techniques has been employed in an optimization model for SWM with diverse focus and objectives [19], for example, smart waste bins. With the development of science and technology, smart waste bins are gradually being introduced. Akhtar et al. [5] established a waste collection model considering the application of smart bins. The research results show that the optimal threshold waste level of waste bin is between $70 \%$ and $75 \%$, and the improved model and algorithm perform better in path optimization. Some researches apply smart waste bins in real cases, including glass bins in Geneva, Switzerland [18] and residential waste bins in the UAE [20]. Maurizio et al. [11] regarded the amount of waste generated as a random variable. Real-time data were acquired through modern 
traceable devices such as RFID, GPRS and GPS, and corresponding rules are set to determine whether waste bins should be collected.

Vehicles are the main mode of waste transportation, which can release a lot of carbon dioxide. Thus, some scholars have studied the carbon emissions in the process. Jabbarzadeh et al. [21] established a model to solve the optimal transportation route with the objective of minimizing greenhouse gas emissions cost in the waste management system. Herold and Lee [22] took 40 global logistics companies as examples and discussed how the extent of the dynamic interaction between internal and external practices influences carbon disclosure strategies. Herold et al. [23] illustrated how the interaction of institutional and stakeholder pressures influences a company's carbon disclosure and depicted four types of carbon disclosure strategies. Edalatpour et al. [24] estimated the average social cost of carbon and the amount of carbon dioxide produced per ton of dry and wet waste. Then sustainable benefits from reducing carbon dioxide emissions are calculated and taken as the benefit component in the objective function.

We can see from the above research that many kinds of waste are considered for collection and transportation from the environmental point of view. However, wet waste which is collected separately has been rarely studied in the implementation of waste classification considering carbon emissions both of driving and idling which is important for the waste collection vehicles. The technology of smart waste bins is widely studied, yet the application of smart waste bins in the stage of waste collection and transportation is rarely considered.

\subsection{Research about Chance-Constrained Programming}

When we consider the waste generation rate, we will be confronted with a stochastic number; therefore, we will need a stochastic programming method to solve the model [24]. The chance-constrained programming technique was introduced by Charnes and Cooper for stochastic programming [25] and has been applied to solve the various kinds of VRPs considering stochastic variables.

Edalatpour et al. [24] established and solved a generic waste management model considering the waste generation rate by a chance-constraint method and analyzed the influence of significant levels on the objective function. Zhang et al. [26] developed a multi-echelon supply model in which the waste generation rate is a stochastic variable, and is transformed into a deterministic constraint. $\mathrm{Xu}$ et al. [27] constructed a model combining a genetic algorithm and fuzzy chance-constrained programming to support SWM under uncertainty conditions, and the applicability of the proposed model was demonstrated by a real reginal waste management issue. Men et al. [28] considered a HazMat equipped vehicle routing problem (H-CVRP) in a type-2 fuzzy environment. Because of the stochastic variable of population density, the objective function involved trapezoidal interval type-1 variables, and was transformed into two equivalent constrains by chance-constrained programming. Kundu et al. [29] proposed a solid transportation problem with fuzzy variables including availability, demands and conveyance capacities, and chance-constrained programming was employed to solved the problem. Kundu et al. [30] investigated multi-objective solid transportation problems considering various uncertainties, including stochastic penalties, fuzzy resource, demands, conveyance capacities and budget. In the model, the uncertain contains are reformulated into deterministic ones by a chance-constrained programing technique.

From the above studies, we can see that chance-constrained programming is effective for stochastic variables, but few articles have applied it to waste generation rates in the field of waste collection and transportation.

\subsection{Research about Some Algorithms for Waste Collection and Transportation}

There are various methods for VRP including metaheuristic, exact method, classic heuristic, real-time solution and simulation [31]. The VRP problem is a NP-hard problem. Therefore, it is natural to use a heuristic to solve the problem [32], such as the adaptive Harmony Search Algorithm (HSA) [33], adaptive Large Neighborhood Search (LNS) algorithm [34], Iterated Greedy Algorithm (IGA) [35], 
Genetic Algorithm (GA) [3] and Particle Swarm Optimization (PSO) algorithm [36], Simulated Annealing Algorithm (SAA) [28,37,38], Multiple Neighborhood Search (MNS) algorithm [24], etc.

Waste collection and transportation is one type of application of VRP, and many studies have solved the VRP in the context of MSW. Jacobsen [39] formulized a municipal solid waste (MSW) collection and transportation problem into a mixed integer program and a heuristic solution was proposed for the problem. Buhrkal et al. [32] studied the waste collection vehicle routing problem with time windows considering worker lunch breaks. The greedy algorithm was employed to construct the initial solution which was improved by the adaptive large neighborhood search with the destroy and repair methods and the results illustrated the usefulness of the algorithm. Hemmelmayr et al. [40] considered a waste collection node routing problem, then the variable neighborhood search and insertion were done by dynamic programming. Schneider et al. [41] was the first person to introduce the vehicle routing problem with intermediate stops (VRPIS). To solve the complex problem, the author combined the strong diversification of varying neighborhood search with an adaptive mechanism to get a highly efficient heuristic, characterized by short computing times and high-quality results.

In summary, the studies about algorithms for waste collection and transportation have appeared extensively but most of them used a single algorithm, rather than a hybrid algorithm which can learn from others' strong points and close the gap. In view of this, the paper proposed a model considering carbon emissions and waste generation rate which will be handled by chance-constrained programming for wet waste collection and transportation.

\section{Model Formulation}

\subsection{Problem Description}

There is a wet waste disposal center used as the depot with a certain number of wet waste collection vehicles and a set of smart waste bins to be collected. The location of the disposal center and each smart waste bin are known. The wet waste volume and quantity can be monitored. The waste generation rate during the period from collection vehicle's departure to smart waste bins is a stochastic parameter and the chance constraint programming is applied to deal with this uncertainty Additionally, the carbon emissions are considered both in driving and idling. The goal of the problem is to find an optimal solution considering the factor of cost, waste generation rate and environment. The detailed assumptions in this paper are as follows:

(1) There is only one type of wet waste collection vehicles with limited capacity.

(2) The location of the depot and each smart waste bin are known.

(3) Each waste generation point has its independent stochastic rate of waste generation and obeys normal distribution [24].

(4) All waste collection vehicles must return the depot when collection tasks completed.

(5) Each smart waste bin is only collected by one vehicle once.

\subsection{Notation}

Based on the needs to establish the model, Table 1 presents the corresponding notation applied in this paper. 
Table 1. Description of symbols.

\begin{tabular}{cl}
\hline Notation & \\
\hline$B$ & Set of smart waste bins $(B=1,2, \cdots, N)$ \\
$V$ & Set of vehicles $(V=1,2, \cdots, K)$ \\
$L$ & Longest length of each route \\
$q_{i}$ & Initial waste of bin $i$ \\
$\Delta q_{i}$ & Incremental waste of bin $i, \Delta q_{i} \sim N\left(\mu_{i}, \sigma_{i}^{2}\right)$ \\
$Q_{0}$ & Weight of vehicle itself \\
$Q_{1}$ & Load weight of vehicle \\
$Q$ & Maximum load capacity of vehicle \\
$\rho_{0}$ & Fuel consumption rate per unit distance while vehicle is empty $(\mathrm{L} / \mathrm{km})$ \\
$\rho$ & Fuel consumption rate per unit distance $(\mathrm{L} / \mathrm{km})$ \\
$\rho^{*}$ & Fuel consumption rate per unit distance while vehicle is at full load $(\mathrm{L} / \mathrm{km})$ \\
$\rho_{i d e l}$ & Fuel consumption rate per unit time while vehicle idling \\
$F_{f u e l}$ & Total amount of fuel consumption $(\mathrm{L} / \mathrm{min})$ \\
$E_{\mathrm{CO}}$ & Total amount of carbon emissions from fuel consumption. \\
$\eta$ & Conversion factor value of fuel consumption and carbon dioxide \\
$\varepsilon$ & Cost of per unit carbon emission \\
$d_{i j}$ & Distance between smart waste bin $i$ and $j$ \\
$t_{i}$ & Service time of smart waste bin $i$ \\
$p_{f}$ & Fixed cost of per unit vehicle \\
$x_{i j k}$ & If the vehicle $k$ visits bin $j$ from $i, x_{\mathrm{ijk}}$ is 1. Otherwise, $x_{i j k}$ is 0 \\
$p$ & Price of per unit fuel consumption
\end{tabular}

\subsection{Model Construction}

The model of waste collection and transportation in this paper takes vehicle cost including the fixed vehicle cost and the variable vehicle cost and the carbon emissions as the objective functions. Above all, we analyze the components of three objective functions separately, and then the specific formulation of the model is determined by these components.

\subsubsection{Analysis of Objectives Function}

1. Vehicle cost

(1) Fixed vehicle cost

Fixed cost refers to the capital cost, insurance cost, tax cost and salvage cost and etc., the total fixed $\operatorname{cost} C_{f}$ in the model can be calculate as:

$$
C_{f}=\sum_{k=1}^{K} \sum_{j=0}^{n} x_{0 j k} p_{f}
$$

(2) Variable vehicle cost

Variable cost refers to the cost of fuel from two activities including driving and idling. Driving means the activity between the collection nodes, idling means the fuel consumption of loading on a certain bin and unload waste. What is more, the distance and load determine the driving fuel, and the idling fuel consumption is dependent on the time of idling [42].

The paper refers to literature [43] to calculate the fuel cost. From the analysis above, we can know fuel consumption rate (FCR) of driving is the linear function of vehicle load, thus, when the load is $Q_{1}$, FCR can be calculated with the equation:

$$
\rho\left(Q_{1}\right)=\rho_{0}+\frac{\rho^{*}-\rho_{0}}{Q} Q_{1}
$$


In the CCLCVRP model, FCR of driving can be expressed as:

$$
\rho_{i j}=\rho_{0}+\frac{\rho^{*}-\rho_{0}}{Q} \sum_{m=0}^{i-1} x_{m l k}\left(q_{m}+\Delta q_{m}\right)
$$

(a) Total fuel cost of driving is calculated as:

$$
C_{\text {fuel-drive }}=\sum_{i=0}^{N} \sum_{j=0}^{N} x_{i j k} d_{i j} \rho_{i j} p
$$

(b) Total fuel cost of idling can be expressed as:

$$
C_{\text {fuel-idel }}=\sum_{j=1}^{N} x_{i j k} t_{j} \rho_{i d e l} p
$$

(c) Total variable vehicle can be calculated by the below equation:

$$
C_{v}=C_{f u e l-d r i v e}+C_{f u e l-i d e l}
$$

\section{Carbon Emissions Cost}

The literature has shown that the carbon emissions of vehicles have a relationship with fuel consumption [44]. The paper uses the following Equation (7) to calculate the amount of carbon dioxide emissions from fuel consumption:

$$
E_{\mathrm{CO}_{2}}=\eta F_{\text {fuel }}
$$

The total amount of fuel consumption is decided by the distance of driving and the time of idling:

$$
\begin{gathered}
F_{\text {fuel }}=\sum_{i=0}^{N} \sum_{j=0}^{N} x_{i j k} d_{i j} \rho_{i j}+\sum_{j=1}^{N} x_{i j k} t_{j} \rho_{i d e l} \\
E_{\mathrm{CO}_{2}}=\eta\left(\sum_{i=0}^{N} \sum_{j=0}^{N} x_{i j k} d_{i j} \rho_{i j}+\sum_{j=1}^{N} x_{i j k} t_{j} \rho_{i d e l}\right)
\end{gathered}
$$

Total carbon emission cost can be calculated as:

$$
C_{c}=\varepsilon E_{\mathrm{CO}_{2}}
$$

\subsubsection{Model Setting}

On the basis of the above analysis, the mathematical model built in the study is as follows:

$$
\operatorname{MinF}=\sum_{k=1}^{K} \sum_{j=0}^{n} x_{0 j k} \rho_{f}+\sum_{i=0}^{N} \sum_{j=0}^{N} x_{i j k} d_{i j} \rho_{i j} p+\sum_{j=1}^{N} x_{i j k} t_{j} \rho_{i d e l} p+\varepsilon \eta\left(\sum_{i=0}^{N} \sum_{j=0}^{N} x_{i j k} d_{i j} \rho_{i j}+\sum_{j=1}^{N} x_{i j k} t_{j} \rho_{i d e l}\right)
$$

Subject to:

$$
\begin{aligned}
& \sum_{k=1}^{K} \sum_{i=0}^{N} x_{i j k}=1, \forall j=1,2, \cdots, N \\
& \sum_{k=1}^{K} \sum_{j=0}^{N} x_{i j k}=1, \forall i=1,2, \cdots, N
\end{aligned}
$$




$$
\begin{gathered}
\sum_{i=0}^{N} x_{i j k}=\sum_{i=0}^{N} x_{j i k}=1, \forall j=1,2 \cdots, N ; k=1,2, \cdots, K \\
\sum_{j=1}^{N} x_{i j k}\left(q_{j}+\Delta q_{j}\right) \leq Q, i=0,1, \cdots, N ; k=1,2, \cdots, K \\
\sum_{i=0}^{N} \sum_{j=0}^{N} d_{i j} x_{i j k} \leq L, \forall k=1,2, \cdots, K, i \neq j \\
\sum_{i=0}^{N} \sum_{j=0}^{N} x_{i j k} \leq|S|-1, S \subseteq\{1,2, \cdots, N\}, \forall k=1,2, \cdots, K
\end{gathered}
$$

The objective function (11) is to minimize the total cost including vehicle cost and carbon emission cost. Constraint (12) shows that each waste bin must be collected once by a vehicle. A vehicle begins at the depot and ends at the last visited customer, which is imposed by Constraint (13) and (14). Constraint (15) represents that the amount of bins for each path cannot larger than the maximum load of the vehicle. The total length for each route does not exceed the longest length of route, which is provided by Constraint (16). Constraint (17) illustrates the subtour elimination.

\subsection{Chance-Constrained Programming}

As an efficient tool for decision making in uncertain environments to hedge risk, chance-constrained programming $(\mathrm{CCP})$ has brought more attention recently. In a CCP problem, decision makers are interested in satisfying a constraint by at least a pre-specified probability at the minimum cost [45]:

$$
\min \psi(x) \text { s.t. } P\{C(x, \xi)\} \geq 1-\gamma x \in X
$$

where $x \in X$ represents the decision variables, $\psi$ often represents a convex cost function, $\xi$ represents a random vector defined on a probability space and the set function $P\{\}$ represents the probability distribution.

Due to the greatly uncertain of waste generation rate [46], it's difficult to predict the amount of generated waste during the period from collection vehicle's departure to smart waste bins, which is set as a stochastic variable in constraint (15). Thus, in order to solve the model, it necessary to convert the uncertain constraint to a certain one by CCP. For the stochastic variable $\Delta q$ in constraint (15) of the CCLCVRP model, the CCP mode is stated as follows:

$$
\operatorname{Pr}\left[\sum_{j=1}^{N} x_{i j k}\left(q_{j}+\Delta q_{j}\right) \leq Q\right] \geq \gamma, i=0,1, \cdots, N ; k=1,2, \cdots, K
$$

where $\gamma$ is the predefined credibility level;

According to $\Delta q_{i} \sim N\left(\mu_{i}, \sigma_{i}^{2}\right)$, we have the following equivalent constraints:

$$
\sum_{j=1}^{N} x_{i j k} \mu_{j}+\Phi^{-1}(\gamma) \sqrt{\sum_{j=1}^{N}\left(x_{i j k}\right)^{2} \sigma_{j}^{2}}+\sum_{j=1}^{N} x_{i j k} q_{j} \leq Q
$$

So far, constraint (15), the stochastic part of the model is transformed into the determined one by chance-constrained programming. 


\section{Algorithm}

\subsection{Algorithm Design}

Because of the NP-hard [47] nature of the proposed problem, which combines CVRP with stochastic variables, exact methods need lots of time to solve large sized problems optimally. Therefore, meta-heuristic algorithms were developed to achieve optimal or near optimal solutions in a reasonable time for large sized problem instances. The meta-heuristic algorithms try to generate some random solutions initially. Then by searching in the neighborhoods of better solutions, they try to find near optimal solutions. Meta-heuristic algorithms are divided into two categories: solution-based and population-based algorithms. Since population-based algorithms have more speed and accuracy in finding optimal solutions [36], a Particle Swarm Optimization (PSO) algorithm is adopted to generated an initial optimal solution. Considered that the problem with PSO is premature convergence and local minima. To avoid this, better exploration is required and hence PSO is equipped with Simulated Annealing (SA) algorithm. SA is a local search-based algorithm that has a mechanism to escape from local optimum with the purpose of finding a global optimum. The PSOSA algorithm detailed flow chart for solving the CCPLCVRP model is shown in Figure 1.

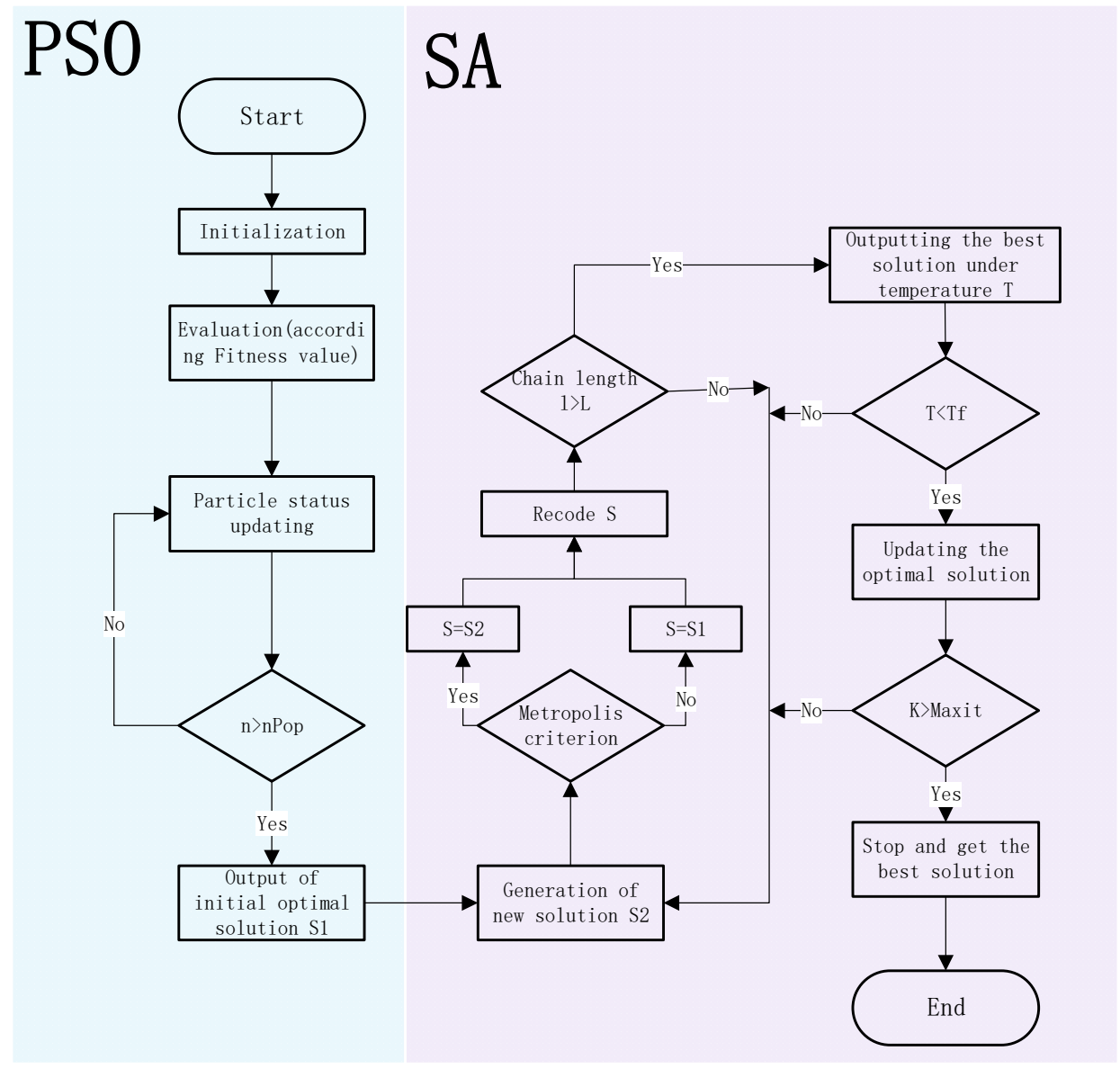

Figure 1. The Flowchart of PSOSA.

\subsection{Encoding and Decoding}

There is a major problem with the PSO algorithm, which is how the position of the particle corresponds to the solution of the model. The encoding and decoding of this particle can ensure that each smart waste bin is served once and that each smart waste bin can be limited to only one vehicle. What is more, the calculation of the solution process can be reduced. This article constructs a coding 
method for the particle, according to literature [44]. All particles are composed of three parts: Part 1 has B particles ( $B$ is the number of smart waste bins), the value of each particle represents the vehicle number as well as the sub-path number to which each smart waste bin belongs and is randomly selected from the natural number of 1 to $\mathrm{V}$; Part 2 has B particles (from 1 to B) which is the sequence number of smart waste bins; Part 3 has B particles(randomly generated between 0-1), the size of the value decides the order of the various smart waste bin in each sub-path.

For example, there is a depot (number 0), 10 smart waste bins (number 1 to 10) and three vehicles (1 to 3). For the following particles:

As displayed in Table 2, the first line is about part1 includes 1, 2 and 3, indicating that there are three vehicles and three sub-paths. Part 2 is showed in the second line from 1 to 10 representing the smart waste bin sequence. It can be seen the smart waste bins of 3, 4, 9 and 10 are allocated to the sub-path1; 2, 5and 7 are allocated to the sub-path2; 1, 6 and 8 are allocated to the sub-path3. Part 3 corresponding to the third line of Table 2 decides the visiting order of each sub-path and to make it clear the fourth line gives the number order of the third line. Each vehicle starts from the depot and back to the depot after finishing their assignment. Thus, the sub-path1 is 0-4-10-3-9-0. The second sub-path is 0-7-2-5-0. The third sub-path is 0-8-6-1-0.

Table 2. Allocation of smart waste bins.

\begin{tabular}{cccccccccc}
\hline 3 & 2 & 1 & 1 & 2 & 3 & 2 & 3 & 1 & 1 \\
\hline 1 & 2 & 3 & 4 & 5 & 6 & 7 & 8 & 9 & 10 \\
\hline 0.7358 & 0.4398 & 0.6832 & 0.3605 & 0.0735 & 0.0884 & 0.9307 & 0.3978 & 0.3530 & 0.7460 \\
\hline 5 & 6 & 9 & 4 & 8 & 2 & 3 & 1 & 10 & 7 \\
\hline Sub-path1 & 0 & 4 & 10 & 3 & 9 & 0 & & & \\
\hline Sub-path 2 & 0 & 7 & 2 & 5 & 0 & & & & \\
\hline Sub-path 3 & 0 & 8 & 6 & 1 & 0 & & & & \\
\hline
\end{tabular}

\subsection{Constructing Initial Optimal Solution Based on PSO Algorithm}

First, we use the PSO algorithm to obtain a high-quality initial solution. When the algorithm starts, each solution in the solution space is considered as a particle. In the shrinking space, each particle has a position to determine its position and a speed to determine its distance and direction.

\subsubsection{Initialization and Fitness Evaluation}

Parameter initialization [44], sets the length of particle code VarSize, the number of population nPop, maximum number of iterations MaxIt, the number of $r_{1}, r_{2}$, acceleration factor $c_{1}, c_{2}$, and the particle range [VarMin, VarMax] and velocity range [-0.1 $\times(\operatorname{VarMax}-\operatorname{VarMin}), 0.1 \times(\operatorname{VarMax}-\operatorname{VarMin})]$. The solution vector is a 1-dimensional variable in this paper. When the particles are initialized, the position and velocity of the $i$-th population can be expressed as:

$$
\begin{aligned}
& x_{i}=\operatorname{rand}(\text { VarSize }) . \times(\text { VarMax }- \text { VarMin })+\text { VarMin } \\
& v_{i}=\operatorname{rand}(\text { VarSize }) . \times(\text { VelMax }- \text { VelMin })+\text { VarMin }
\end{aligned}
$$

All particles have a fitness value to evaluate the strength that is determined by the fitness function, which is calculated based on the cost of each route.

\subsubsection{Determining Optimal Solution}

In each iteration, each particle has an individual extremum, which is expressed as $p^{\text {best }}$ and all particles share a global extremum, which is expressed as $g^{\text {best }}$. Particles follow the individual extremes and global extremes to search in the solution space and find the optimal solution. 


\subsubsection{Particle Status Update}

Each time the position and velocity are updated according to Equation (23):

$$
\left\{\begin{array}{c}
v_{i+1}=\omega_{i+1} v_{i}+c_{1} r_{1}\left(p^{\text {best }}-x_{i}\right)+c_{2} r_{2}\left(g^{\text {best }}-x_{i}\right) \\
\text { If } v_{i+1}>v_{\text {max }}, v_{i+1}=v_{\text {max }} \\
\text { If } v_{i+1}<v_{\text {min }}, v_{i+1}=v_{\text {min }} \\
x_{i+1}=x_{i}+v_{i+1}
\end{array}\right.
$$

Generally, to improve the convergence of the particles, inertia weight $(\omega)$ is used. Since the search space is complex, a time variant inertia weight is used which is specified in Equation (24):

$$
\omega_{i+1}=\omega_{i} \times w d a m p
$$

In Equation (24) wdamp is the inertia weight damping ratio, which is between 0-1. Initially, a high inertia weight is used leading to high global exploration. As the iteration progresses, the inertia weight is lowered to guide local exploitation.

\subsubsection{Terminating Condition}

Finally, when the greatest population number $n P o p$ appears is the end of the condition. Otherwise, it will continue to evolve.

\subsection{Structure Global Optimal Solution Based on SA}

This paper combines annealing algorithm with the particle swarm optimization algorithm in order to make for the shortcoming of poor local search ability of the particle swarm optimization algorithm and produce a high quality solution.

\subsubsection{Initialization and Initial Solution}

Parameter initialization, set the initial temperature $T_{0}$, the final temperature $T_{\text {end }}$, the chain length for each temperature $L$. The optimal solution obtained by PSO algorithm is set as the initial solution of SA algorithm.

\subsubsection{Generation of New Solution}

If the new solution is not as good as the initial solution, it is not necessarily discarded. Thus, Metropolis criterion is invoked to determine whether to accept a worse solution or not which is described as Equation (25):

$$
p=\left\{\begin{array}{c}
\exp \left(-\frac{\Delta f}{T_{i}}\right), \Delta f \geq 0 \\
1, \Delta f<0
\end{array}\right.
$$

New solution is newsolu, the objective function value is newobjv, and $\Delta f$ is used to represent the increment of the objective function, $\Delta f=n e w o b j-o b j v . T_{i}$ is the current temperature. If newobjv is less than $o b j$, the new solution is unconditionally accepted. If newobjv is higher than $o b j$, the probability of acceptance of the new solution is $p=\exp \left(-\frac{\Delta f}{T_{i}}\right)$.

For each temperature, a series of $L$ attempts are performed to explore the space and the best solution under each temperature is recorded.

\subsubsection{Cooling Operation}

During the process, the temperature decreases by multiplying the cooling coefficient $r$ to enforce the convergence as is shown by Equation (26):

$$
T_{i+1}=T_{i} \times r
$$




\subsubsection{Terminating Condition}

Finally, that the temperature $T_{i}$ is lower than the final temperature $T_{\text {end }}$ is the end of the condition. Otherwise, it will continue to evolve.

\section{Numerical Experiments and Analysis}

\subsection{Algorithm Experiment}

In this section,10 cases (A-n32-k5, A-n36-k5, A-n46-k7, A-n53-k7, A-n62-k8, A-n80-k10, B-n51-k7, F-n135-k7, P-n76-k5 and P-n101-k4) are chosen from the typical database in CVRP to test the applicability of design PSOSA algorithm. Table 3 shows the information about the test instances which includes the number of nodes and the capacity of vehicles. The related parameters are set according to the literature $[37,48,49]$, as shown in Table 4 . In this study, the traditional PSO algorithm is compared with the proposed PSOSA algorithm. Each of the following experiments is executed 20 times with Matlab R2016b on a PC with Intel core i5 CPU operating at $2.60 \mathrm{GHz}$. The best value is recorded as the optimal results. Table 5 shows the detailed computational results of PSO and PSOSA.

Table 3. Data about the test instances.

\begin{tabular}{ccc}
\hline Case & Node & Capacity \\
\hline A-n32-k5 & 31 & 100 \\
A-n36-k5 & 35 & 100 \\
A-n46-k7 & 45 & 100 \\
A-n53-k7 & 52 & 100 \\
A-n62-k8 & 61 & 100 \\
A-n80-k10 & 79 & 100 \\
B-n51-k7 & 50 & 100 \\
F-n135-k7 & 134 & 2210 \\
P-n76-k5 & 75 & 280 \\
P-n101-k4 & 100 & 400 \\
\hline
\end{tabular}

Table 4. Parameters of PSOSA.

\begin{tabular}{ccc}
\hline Description & Parameter & Value \\
\hline Number of the population & $N_{p}$ & 20 \\
Inertia weight & $\omega$ & 0.7 \\
Inertia weight damping ratio & $\omega$ damp & 0.99 \\
Personal learning coefficient & $c_{1}$ & 1.5 \\
Global learning coefficient & $c_{2}$ & 1.5 \\
Evolution terminate generation & $M_{p}$ & 1000 \\
Initial temperature & $T_{0}$ & 1000 \\
Cooling coefficient & $r$ & 0.9 \\
Final temperature & $T_{\text {end }}$ & 1 \\
\hline
\end{tabular}


Table 5. Results of PSO and PSOSA.

\begin{tabular}{ccccccc}
\hline \multirow{2}{*}{ Database } & \multicolumn{3}{c}{ PSO } & \multicolumn{3}{c}{ PSOSA } \\
\cline { 2 - 6 } & Cost & Length & $\begin{array}{c}\text { Carbon } \\
\text { Emissions }\end{array}$ & Cost & Length & $\begin{array}{c}\text { Carbon } \\
\text { Emissions }\end{array}$ \\
\hline A-n32-k5 & 3889 & 1628 & 1628 & 3587 & 1543 & 974 \\
A-n36-k5 & 6005 & 1623 & 1127 & 5256 & 1454 & 1005 \\
A-n46-k7 & 5039 & 2075 & 1419 & 4771 & 1893 & 1382 \\
A-n53-k7 & 6982 & 2925 & 2090 & 3856 & 2463 & 1918 \\
A-n62-k8 & 10,449 & 3043 & 2367 & 9035 & 2766 & 2053 \\
A-n80-k10 & 15,103 & 4531 & 2836 & 9997 & 4471 & 2641 \\
B-n51-k7 & 8552 & 2864 & 1905 & 6203 & 2648 & 1697 \\
F-n135-k7 & 14,645 & 5946 & 5876 & 12,906 & 5671 & 4052 \\
P-n76-k5 & 10,227 & 2573 & 1390 & 9576 & 2369 & 1237 \\
P-n101-k4 & 7091 & 2865 & 1762 & 6739 & 2680 & 1628 \\
\hline
\end{tabular}

Figure 2 shows some values of the iterative process of PSOSA algorithm. It can be seen in Figure 2 that the highest fitness value has been obtained when the number of iterations of the PSOSA algorithm is less than 500. We can easily see from Table 5 that, compared with the PSO algorithm, the results obtained by PSOSA including the total cost, the carbon emissions and the route length are better. Overall, they have a great improvement in the quality of the solution. Thus, the proposed PSOSA algorithm in this paper is effective and competitive in tackling VRP.

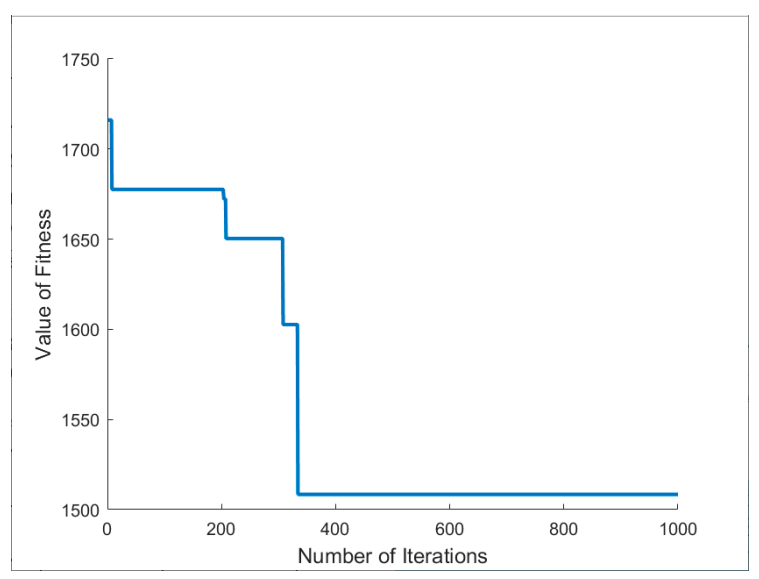

Figure 2. Convergence results of PSOSA algorithm.

\subsection{Model Experiment}

\subsubsection{Experimental Design}

The distribution data of a vehicle routing problem concerning waste collection and transportation, which is referred from [50], is used to verify the CCLCVRP model. There is one wet waste disposal center used as the depot and several waste collection vehicles of the same kind with a capacity of $2000 \mathrm{~kg}$. There are 30 smart waste bins to be collected. Considering that the study is aimed at wet waste, the waste amount in original data is processed by multiplied by $60 \%$.

Detailed information is displayed in Table 6, including of the position and amount of waste. And we set the other parameters of the CCLCVRP model according to the former studies [44,51,52], which are shown in Table 7. 
Table 6. Information about the Depot and Smart Waste Bins.

\begin{tabular}{|c|c|c|c|}
\hline Point & X Coordinate & Y Coordinate & Amount of Waste \\
\hline Depot & 2.3 & 2.12 & - \\
\hline 1 & 0.98 & 0.08 & 376.122 \\
\hline 2 & 3.6 & 1.05 & 339.786 \\
\hline 3 & 3.35 & 2.68 & 463.5 \\
\hline 4 & 1.92 & 4.27 & 548.34 \\
\hline 5 & 2.46 & 4.55 & 551.1 \\
\hline 6 & 3.87 & 1.67 & 550.002 \\
\hline 7 & 0.74 & 2.35 & 361.116 \\
\hline 8 & 2.43 & 0.01 & 463.326 \\
\hline 9 & 0.36 & 1.55 & 562.482 \\
\hline 10 & 3.94 & 2.43 & 336.3 \\
\hline 11 & 1.97 & 1.31 & 556.908 \\
\hline 12 & 1.18 & 3.42 & 569.934 \\
\hline 13 & 0.4 & 4.56 & 365.358 \\
\hline 14 & 0.4 & 2.85 & 323.094 \\
\hline 15 & 4.64 & 1.33 & 442.266 \\
\hline 16 & 1.02 & 4.64 & 550.506 \\
\hline 17 & 4.78 & 0.32 & 440.82 \\
\hline 18 & 1.7 & 3.13 & 424.128 \\
\hline 19 & 0.3 & 0.54 & 450.822 \\
\hline 20 & 1.72 & 2.58 & 337.632 \\
\hline 21 & 3.02 & 4.78 & 339.684 \\
\hline 22 & 3.06 & 1.36 & 561.144 \\
\hline 23 & 2.78 & 2.63 & 480.888 \\
\hline 24 & 2.73 & 3.56 & 379.59 \\
\hline 25 & 1.01 & 1.07 & 559.44 \\
\hline 26 & 3.94 & 4.13 & 317.43 \\
\hline 27 & 1.74 & 0.69 & 437.328 \\
\hline 28 & 4.86 & 2.19 & 516.66 \\
\hline 29 & 0.58 & 3.88 & 401.7 \\
\hline 30 & 3.56 & 3.52 & 420.366 \\
\hline
\end{tabular}

Table 7. Parameters related to the objective function.

\begin{tabular}{cc}
\hline Parameters & Value \\
\hline$p_{f}$ & $100 \mathrm{CNY}$ \\
$p$ & $8 \mathrm{CNY} / / \mathrm{L}$ \\
$\rho_{0}$ & $0.165 \mathrm{~L} / \mathrm{km}$ \\
$\rho^{*}$ & $0.377 \mathrm{~L} / \mathrm{km}$ \\
$\rho_{i d e l}$ & $0.05 \mathrm{~L} / \mathrm{min}$ \\
$\eta$ & $2.63 \mathrm{~kg} / \mathrm{L}$ \\
$\varepsilon$ & $0.025 \mathrm{CNY} / \mathrm{kg}$ \\
\hline
\end{tabular}

\subsubsection{Experimental Results}

1. Experimental Results of Comparison between CCP and EVM

CCP is an efficient tool to solve the stochastic problem and credibility level $\gamma$ in CCP is predetermined representing the probability of path success without overloading and reflecting the dispatcher's risk preference. The higher the $\gamma$, the lower the risk. Firstly, the comparison experiment with Expected Value Method (EVM) is designed to verify the rationality of CCP. EVM refers to the incremental amount of waste is predicted according to the average values without considering 
disturbance factor [53]. In order to evaluate the solution of the two methods more effectively, the robustness [53] of the solution is defined, as is stated in Equation (27):

$$
\text { Robustness }=\operatorname{Pr}\left[\sum_{j=1}^{N} x_{i j k}\left(q_{j}+\Delta q_{j}\right) \leq Q\right]
$$

The robustness of the solution indicates the probability of path success, that is, the probability of not overloading. The EVM and CCP with different $\gamma$ are implemented 20 times and the robustness is shown in Table 8.

Table 8. the Robustness of EVM and CCP.

\begin{tabular}{lcccccc}
\hline \multirow{2}{*}{ Results } & EVM & \multicolumn{5}{c}{ CCP $(\gamma)$} \\
\cline { 3 - 7 } & & $\mathbf{0 . 6}$ & $\mathbf{0 . 7}$ & $\mathbf{0 . 8}$ & $\mathbf{0 . 9}$ & $\mathbf{0 . 9 9}$ \\
\hline Robustness & $45 \%$ & $55 \%$ & $75 \%$ & $80 \%$ & $90 \%$ & $97 \%$ \\
\hline
\end{tabular}

We can see from Table 8, EVM has a lower robustness, while the CCP has a higher one which is close to the predefined credibility levels $(\gamma)$.

2. Experimental Results of WFLs and Credibility Levels

Different combinations of WFLs and credibility levels will result in different optimal solutions. Thus, secondly, we do the following experiments to achieve optimal optimization. Each experiment is implemented 20 times, and the numerical value with the best result is recorded.

In order to evaluate the solution more comprehensively, two concepts are introduced, tightness and unit cost. Tightness [54] is estimated by calculating the amount of waste carried per unit vehicle capacity, as shown in Equation (28). Unit cost is about the collection cost of per unit waste and is stated in Equation (29):

$$
\begin{gathered}
\text { Tightness }=\frac{\text { Total collected waste }}{\text { NO.of vehicles } \times \text { Capacity of vehicles }} \\
\text { Unit Cost }=\frac{\text { Total cost }}{\text { Total collected waste }}
\end{gathered}
$$

Then we do two initial experiments: (1) an experiment about WFLs in a static environment, that is, no consideration of $\gamma$; (2) an experiment about $\gamma$, that is, WFL $=0$. Finally, we do a sensitivity analysis of WFLs under different credibility levels.

(i) Experimental Results of WFLs

We consider seven WFLs, namely, 0, 0.6, 0.65, 0.7, 0.75, 0.8 and 0.9 [54], to compute an efficient waste collection route, and waste bin exceeding a certain WFL needs to be collected. Table 9 shows the obtained results, including total cost $(C)$, carbon emissions $(C E)$, total length $(L)$, improvement $(I)$, the number of collected smart waste bins $(n)$, the number of vehicles used $(N)$, detail route (Route), total collected waste $(T C W)$, the percentage of total collected waste $\left(T C W_{p}\right)$, tightness $(T)$ and unit cost (UC).The applying of WFL concept shows impressive results on smart waste bin efficiency compared with the conventional pattern $(\mathrm{WFL}=0)$. The model showed improved results when using the smart waste bin. With the increase of WFL, the total cost, carbon emissions and total length decrease and the fifth column shows the improvement in total cost under different WFLs compared with conventional pattern. Obviously, the increase in WFL leads to the drop both in the number of collected smart waste bins and the number of vehicles. To illustrate the impact of smart waste bins on environment, Figure 3 shows the carbon emissions at different WFLs. We can see carbon emission reached a highest value without the use of smart waste bins $(\mathrm{WFL}=0)$ and carbon emissions decrease, as WFL increases. To better explain the change in tightness and efficiency, the results are shown in Figure 4. Generally, the 
less unit cost means the better savings of cost and carbon emissions, and the higher tightness means the good savings of distance. Figure 4 shows that we can get the good value both of tightness and unit cost at the WFL of 0.7 for the database.

Table 9. Obtained detailed results by applying the WFL concept.

\begin{tabular}{|c|c|c|c|c|c|c|c|c|c|c|c|}
\hline WFL & $C$ & $C E$ & $L$ & $I$ & $n$ & $N$ & Route & $T C W$ & $T C W_{p}$ & $T$ & $U C$ \\
\hline $\mathrm{WFL}=0$ & 945 & 80 & 91 & $0 \%$ & 30 & 7 & $\begin{array}{c}(0,11,3,29,4,0) \\
(0,23,26,9,5,0) \\
(0,20,17,18,14,8,0) \\
(0,12,24,25,30,0) \\
(0,7,28,10,6,0) \\
(0,16,22,15,2,0) \\
(0,27,19,21,1,13,0)\end{array}$ & 13,428 & $100 \%$ & $96 \%$ & 0.07035 \\
\hline $\mathrm{WFL}=0.9$ & 350 & 16 & 18 & $63 \%$ & 9 & 3 & $\begin{array}{l}0,7,1,2,0) \\
(0,9,4,6,0) \\
(0,3,8,5,0)\end{array}$ & 5010 & $37 \%$ & $83 \%$ & 0.06983 \\
\hline $\mathrm{WFL}=0.8$ & 460 & 20 & 23 & $51 \%$ & 11 & 4 & $\begin{array}{c}(0,4,10,5,0) \\
(0,2,6,0) \\
(0,1,7,9,0) \\
(0,11,3,8,0)\end{array}$ & 6007 & $45 \%$ & $75 \%$ & 0.07659 \\
\hline $\mathrm{WFL}=0.75$ & 583 & 27 & 31 & $38 \%$ & 14 & 5 & $\begin{array}{c}(0,6,9,8,0) \\
(0,5,1,0) \\
(0,10,13,7,0) \\
(0,12,2,3,0) \\
(0,11,14,4,0)\end{array}$ & 7385 & $55 \%$ & $74 \%$ & 0.07889 \\
\hline $\mathrm{WFL}=0.7$ & 632 & 43 & 47 & $33 \%$ & 19 & 5 & $\begin{array}{c}(0,18,16,17,5,0) \\
(0,6,2,3,0) \\
(0,4,9,7,13,0) \\
(0,12,15,1,14,0) \\
(0,19,10,8,11,0)\end{array}$ & 9550 & $71 \%$ & $96 \%$ & 0.06618 \\
\hline $\mathrm{WFL}=0.65$ & 728 & 42 & 48 & $23 \%$ & 20 & 6 & $\begin{array}{c}(0,1,15,20,4,0) \\
(0,8,18,11,9,0) \\
([0,2,16,14,0) \\
(0,5,17,13,6,0) \\
(0,19,3,7,0) \\
(0,10,12,0)\end{array}$ & 9952 & $74 \%$ & $83 \%$ & 0.07312 \\
\hline $\mathrm{WFL}=0.6$ & 776 & 58 & 67 & $18 \%$ & 24 & 6 & $\begin{array}{c}(0,23,11,10,17,0) \\
(0,6,15,22,20,0) \\
([0,19,9,8,18,0) \\
(0,13,1,16,12,0) \\
(0,14,7,21,3,0) \\
(0,24,5,4,2,0)\end{array}$ & 11,434 & $85 \%$ & $95 \%$ & 0.06791 \\
\hline
\end{tabular}

\section{(ii) Experimental Results of Credibility Levels}

The amount of waste generated within the waste generation points are not always determined over time, so we realistically consider the waste generation rate as a stochastic parameter. This means that when collection vehicles depart from the depot according to the schedule and the amount of waste in smart waste bins, there will be an incremental of waste amount in smart waste bins as travelling time elapses, so a chance constraint method is applied to deal with this uncertainty and credibility levels are predefined to insure the probability of routes' success. The means and standard deviations of the incremental for each bin are random assigned values, respectively.

We do the sensitivity analysis under the condition of WFL $=0$ (all the smart waste bins will be collected according to the schedule). Obviously, the objective function varies with the predefined credibility levels and the objective values of the same solution are different with different credibility levels. As shown in Figure 5, the total cost of this optimal solution increase and the number of vehicles does not reduce as $\gamma$ increases. It is worth mentioned that for $\gamma=[0.5,0.6],[0.85,0.9]$ and $[0.95,0.99]$, the total cost of optimal solution has a sharp increase with the number of vehicles grows. For other 
point, there is a slight change. The predetermined $\gamma$ reflects the dispatchers' different attitudes toward risk [55]. dispatchers can accept the risk brought by path failure with a lower $\gamma$; otherwise, dispatchers hope the actual amount of waste will be less than the expected one with a high $\gamma$ to avoid overloading.

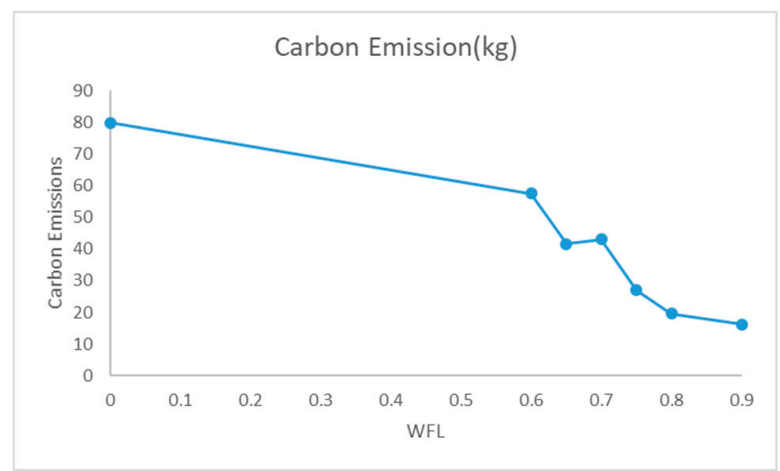

Figure 3. Caron Emissions at Different WFLs.

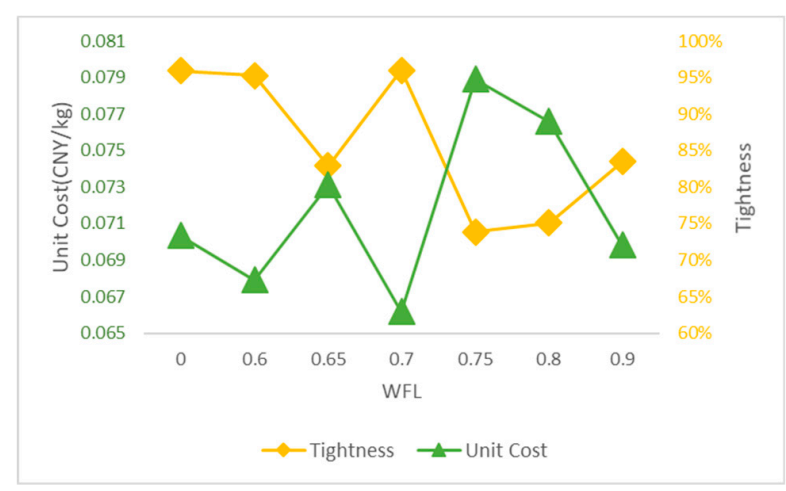

Figure 4. Changes of Tightness and Efficiency at Diffident WFLs.

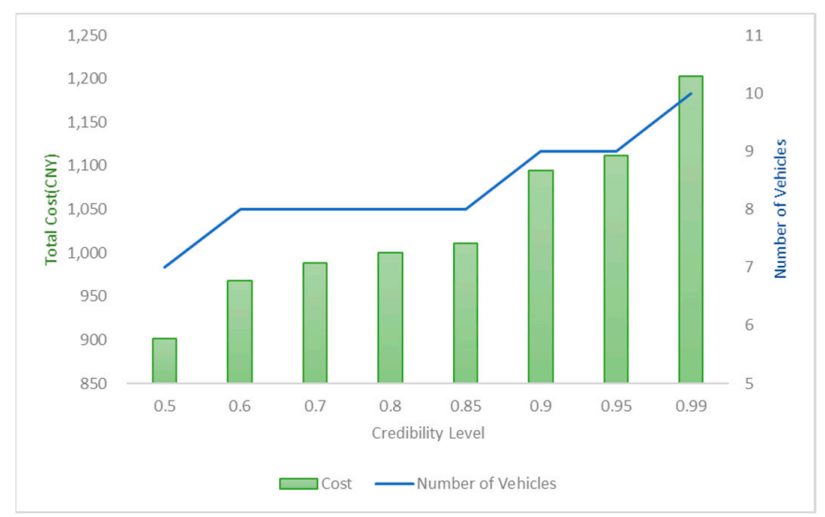

Figure 5. Total Cost and Number of Vehicles under Different Credibility Level $\gamma$.

3. Experiment results of WFLs under different $\gamma$

This section deals with the improvement in waste collection and route optimization by implying smart waste bins under different credibility levels. As shown in Figure 6, we adopt the different predefined credibility levels $\gamma$ of $0.99,0.95,0.9,0.85,0.8,0.7,0.6$ and 0.5 to obtain the tightness and unit cost of the optimal solutions under different WFLs. The results illustrate that both of the higher tightness above $80 \%$ and lower cost about $0.07 \mathrm{CNY} / \mathrm{kg}$ are generated at 0.65 or 0.75 of WFL. If 0.9 of WFL is considered, the high efficiency can be realized, however, the collected waste percentage is less than $60 \%$ under all the predefined credibility levels, which will be inconvenient for waste 
collection vendors. Taking Figure $6 \mathrm{~d}$ for example, we can see the better solution can be obtained at the WFL of 0.7 with $91 \%$ tightness, $0.068 \mathrm{CNY} / \mathrm{kg}$ of unit cost and $87 \%$ collected waste percentage under the credibility level of 0.85 . Although the efficiency is not bad at WFL of 0.9 , the total collected waste percentage is about $35 \%$, which is too little to leading to overflowing for some smart waste bins. Nevertheless, for different credibility levels, the set of WFL at 0.65 or 0.75 provides the most efficient and optimized values.

(a)

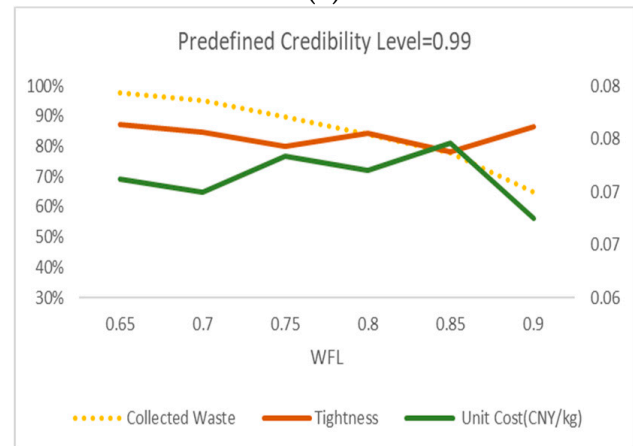

(c)

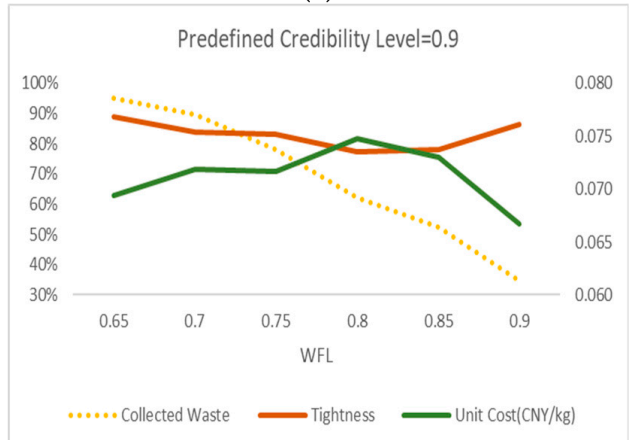

(e)

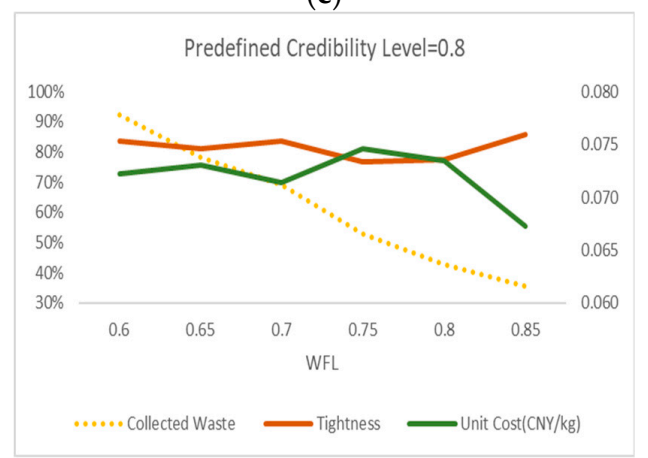

(g)

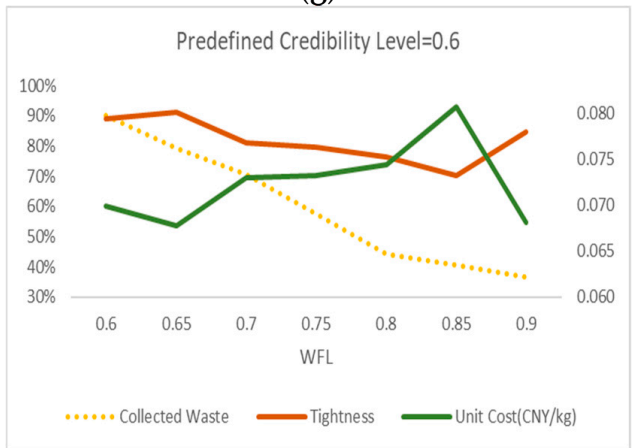

(b)

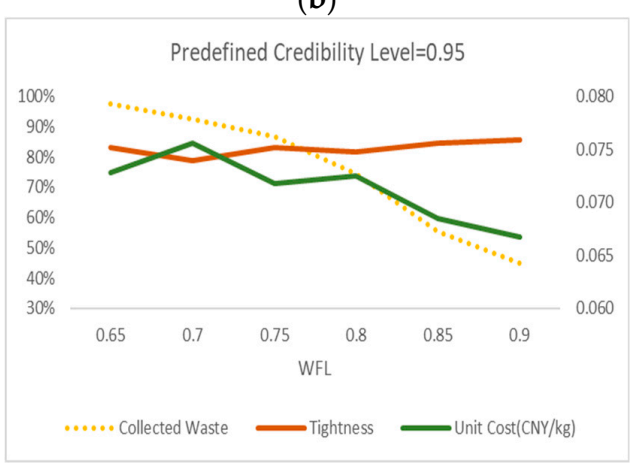

(d)

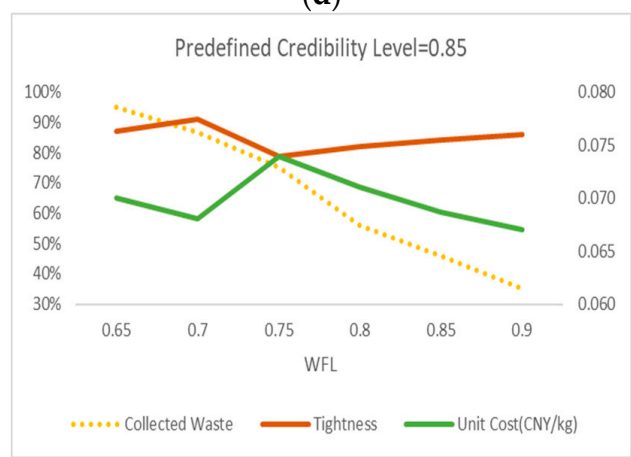

(f)

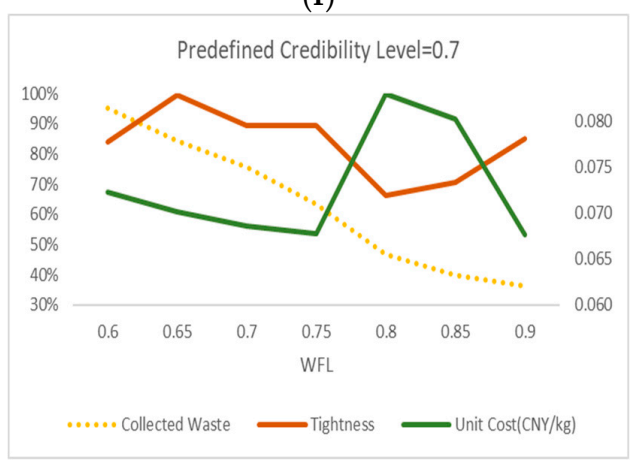

(h)

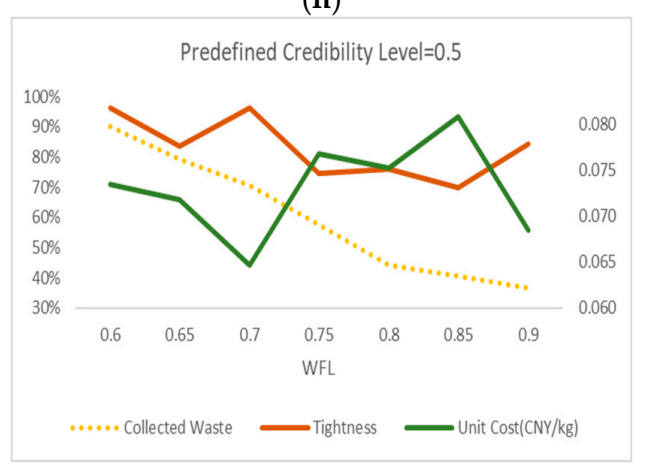

Figure 6. The changes of tightness, unit cost and collected waste percentage under different $\gamma$. 


\subsection{Analysis of Results}

For the VRP in waste management, the CCLCVRP model is built in this paper aiming at the optimization of the wet waste collection and transportation system. Under the application of smart waste bins, we study the impact of different WFLs and credibility levels on the total cost, unit cost, tightness and the percentage of collected waste. Obviously, it is difficult to determine a certain optimal value of WFL under different credibility levels, because it will change as various factors change, including the waste management decision, waste generation rate and so on. However, we can confirm a value range of WFL to achieve the overall optimality of the waste collection and transportation system with the application of smart waste bins. In this paper, by assigning different numerical combination of WFLs and credibility levels, we obtain the optimal solutions by PSOSA. The main summings-up are listed as follows:

(1) For experiment 1, when the WFL is increasing, all of the total cost, carbon emissions and route length decrease, and the unit cost and tightness fluctuate. In the static environment, there is a certain WFL of 0.75 with the minimum unit cost and the highest tightness.

(2) For experiment 2, when $\gamma \in[0.8,1)$, the dispatcher is the risk aversion type, expecting to plan more vehicles to obtain higher path reliability; when $\gamma \in[0.5,0.8)$, the manager is the risk preference type, thinking that the overloading risk caused by uncertain environment can be accepted.

(3) For experiment 3, in the range between 0.65 and 0.75 of WFL, the waste transportation obtains the overall optimality under different credibility levels.

(4) Through setting different value of WFLs and credibility levels, it is proved that the CCLCVRP model is applicable for waste collection and transportation.

Based on the above results, some constructive suggestions are put forward. From the perspective of waste collection and transportation organizations, they can apply scientific ways such as path optimization methods and technical means such as smart waste bins to reduce the total cost. In a static environment, the WFL of 0.75 is a good choice to ensure the efficiency of waste collection and transportation. In a stochastic environment, a credibility level should be set in accordance with dispatcher's risk preference, then make the best use of smart waste bins to choose the optimum WFL between 0.65 and 0.75 to obtain the maximum tightness, minimum unit cost, and appropriate collected waste percentage.

From the perspective of government environment departments, firstly, they'd better introduce some relevant policies to accelerate the application of smart waste bins to raise the efficiency of waste management system. Secondly, they must strengthen people's awareness of environmental protection, and encourage the enterprise to save energy and reduce carbon emissions.

\section{Conclusions}

With the development of intelligent technology, smart waste bins have been applied in some regions of China, which can rise the efficiency of SWM. Waste collection and transportation is a high-carbon emissions stage in SWM with a stochastic waste generation rate. It is necessary to optimize the waste collection routes while taking into environmental benefits based on the data from smart waste bins. In this paper, based on the application of smart waste bins, a comprehensive CCLCVRP model, with the minimized total cost including vehicle cost and carbon emissions cost, is designed to optimize the wet waste collection and transportation paths. An improved genetic algorithm, PSOSA, is introduced to solve the model. Moreover, the numerical experiments are used to verify the effectiveness of the algorithm. Then a case data is used to validate the established model. The minimum total cost, the tightness, unit cost and total collected waste percentage are calculated respectively as the reference for subsequent experiments with different WFLs and credibility levels. Based on the results, some suggestions are provided for the department of waste management and waste collection and transportation organizations. In future research, the CCLCVRP based on the application of smart 
waste bins can consider multiple vehicle types and all kind of waste. In addition, real data can be used to get some more realistic and reliable examples.

Author Contributions: Conceptualization, H.W.; methodology, H.W.; software, H.W.; validation, Q.Q. and F.T.; formal analysis, H.W.; investigation, M.Z.; resources, H.W.; data curation, Q.Q.; writing—original draft preparation, H.W.; writing-review and editing, H.W. and F.T.; visualization, F.T.; supervision, F.T.; project administration, F.T.; funding acquisition, F.T. All authors have read and agreed to the published version of the manuscript.

Funding: This research received no external funding.

Acknowledgments: The funding supports from the Natural Science Foundation Project of Chongqing (cstc2019jcyj-msxmX0100).

Conflicts of Interest: The authors declare no conflict of interest.

\section{References}

1. Hemidat, S.; Oelgemöller, D.; Nassour, A.; Nelles, M. Evaluation of Key Indicators of Waste Collection Using GIS Techniques as a Planning and Control Tool for Route Optimization. Waste Biomass Valorization 2017, 8, 1533-1554. [CrossRef]

2. Erfan, B.T.; Alireza, G.; Maryam, P.; Ramina, M.K. A robust bi-objective multi-trip periodic capacitated arc routing problem for urban waste collection using a multi-objective invasive weed optimization. Waste Manag. Res. 2019, 37, 1089-1101.

3. Assaf, R.; Saleh, Y. Vehicle-Routing Optimization for Municipal Solid Waste Collection Using Genetic Algorithm: The Case of Southern Nablus City. Civ. Environ. Eng. Rep. 2017, 26, 43-57. [CrossRef]

4. Christopher, C.J.; Mondal, M.M.; Weichgrebe, D. Evaluation of compositional characteristics of organic waste shares in municipal solid waste in fast-growing metropolitan cities of India. J. Mater. Cycles Waste Manag. 2018, 20, 2150-2162.

5. Akhtar, M.; Hannan, M.A.; Begum, R.A.; Basri, H.; Scavino, E. Backtracking search algorithm in CVRP models for efficient solid waste collection and route optimization. Waste Manag. 2017, 61, 117-128. [CrossRef]

6. Ding, Z.; Zhu, M.; Tam, V.W.Y.; Yi, G.; Tran, C.N.N. Asystem dynamics based environmental benefit assessment model of construction waste reduction management at the design and construction stages. J. Clean. Prod. 2018, 176, 676-692. [CrossRef]

7. Ghose, M.K.; Dikshit, A.K.; Sharma, S.K. A GIS based transportation model for solid waste disposal-A case study on Asansol municipality. Waste Manag. 2005, 26, 1287-1293. [CrossRef]

8. Zhou, M.; Shen, S.; Xu, Y.; Zhou, A. New Policy and Implementation of Municipal Solid Waste Classification in Shanghai, China. Int. J. Environ. Res. Public Health 2019, 16, 3099. [CrossRef]

9. Expósito-Márquez, A.; Expósito-Izquierdo, C.; Brito-Santana, J.; Moreno-Pérez, J.A. Greedy randomized adaptive search procedure to design waste collection routes in La Palma. Comput. Ind. Eng. 2019, 137, 106047. [CrossRef]

10. Kwon, Y.-J.; Choi, Y.-J.; Lee, D.-H. Heterogeneous fixed fleet vehicle routing considering carbon emission. Transp. Res. Part D Transp. Environ. 2013, 23, 81-89. [CrossRef]

11. Maurizio, F.; Alessandro, P.; Giorgia, Z. Waste collection multi objective model with real time traceability data. Waste Manag. 2011, 31, 2391-2405.

12. Zsigraiova, Z.; Semiao, V.; Beijoco, F. Operation costs and pollutant emissions reduction by definition of new collection scheduling and optimization of MSW collection routes using GIS. The case study of Barreiro, Portugal. Waste Manag. 2013, 33, 793-806. [CrossRef] [PubMed]

13. Arebey, M.; Hannan, M.A.; Begum, R.A.; Basri, H. Solid waste bin level detection using gray level co-occurrence matrix feature extraction approach. J. Environ. Manag. 2012, 104, 9-18. [CrossRef] [PubMed]

14. Hannan, M.A.; Al Mamun, M.A.; Hussain, A.; Basri, H.; Begum, R.A. A review on technologies and their usage in solid waste monitoring and management systems: Issues and challenges. Waste Manag. 2015, 43, 509-523. [CrossRef]

15. Hannan, M.A.; Arebey, M.; Begum, R.A.; Basri, H. Radio Frequency Identification (RFID) and communication technologies for solid waste bin and truck monitoring system. Waste Manag. 2011, 31, 2406-2413. [CrossRef]

16. Kim, B.I.; Kim, S.; Sahoo, S. Waste collection vehicle routing problem with time windows. Comput. Oper. Res. 2005, 33, 3624-3642. [CrossRef] 
17. Asefi, H.; Shahparvari, S.; Chettri, P.; Lim, S. Variable fleet size and mix VRP with fleet heterogeneity in Integrated Solid Waste Management. J. Clean. Prod. 2019, 230, 1376-1395. [CrossRef]

18. Markov, I.; Bierlaire, M.; Cordeau, J.F.; Maknoon, Y.; Varone, S. Waste Collection Inventory Routing with Non-Stationary Stochastic Demands. Comput. Oper. Res. 2019, 113, 104798. [CrossRef]

19. Singh, A. Solid waste management through the applications of mathematical models. Resour. Conserv. Recycl. 2019, 151, 104503. [CrossRef]

20. Abdallah, M.; Adghim, M.; Maraqa, M.; Aldahab, E. Simulation and optimization of dynamic waste collection routes. Waste Manag. Res. 2019, 37, 793-802. [CrossRef]

21. Jabbarzadeh, A.; Darbaniyan, F.; Jabalameli, M.S. A multi-objective model for location of transfer stations: Case study in waste management system of Tehran. J. Ind. Syst. Eng. 2016, 9, 109-125.

22. Herold, D.M.; Lee, K.-H. The influence of internal and external pressures on carbon management practices and disclosure strategies. Australas. J. Environ. Manag. 2019, 26, 63-81. [CrossRef]

23. Herold, D.M.; Farr, B.; Lee, K.-H.; Groschopf, W. The interaction between institutional and stakeholder pressures: Advancing a framework for categorising carbon disclosure strategies. Bus. Strategy Dev. 2018, 2, 77-90. [CrossRef]

24. Edalatpour, M.A.; Al-e-hashem, S.M.J.M.; Karimi, B.; Bahli, B. Investigation on a novel sustainable model for waste management in megacities: A case study in tehran municipality. Sustain. Cities Soc. 2018, 36, $286-301$. [CrossRef]

25. Charnes, A.; Cooper, A.A. Chance-Constrained Programming. Manag. Sci. 1959, 6, 73-79. [CrossRef]

26. Zhang, Y.; Huang, G.; He, L. A multi-echelon supply chain model for municipal solid waste management system. Waste Manag. 2014, 34, 553-561. [CrossRef]

27. Xu, Y.; Liu, X.; Hu, X.; Huang, G.; Meng, N. A genetic-algorithm-aided fuzzy chance-constrained programming model for municipal solid waste management. Eng. Optimiz. 2019, 1-17. [CrossRef]

28. Men, J.; Jiang, P.; Xu, H. A chance constrained programming approach for HazMat capacitated vehicle routing problem in Type-2 fuzzy environment. J. Clean. Prod. 2019, 237, 117754. [CrossRef]

29. Kundu, P.; Majumder, S.; Kar, S.; Maiti, M. A method to solve linear programming problem with interval type-2 fuzzy parameters. Fuzzy Optim. Decis. Mak. 2019, 18, 109-130. [CrossRef]

30. Kundu, P.; Kar, S.; Maiti, M. Multi-objective solid transportation problems with budget constraint in uncertain environment. Int. J. Syst. Sci. 2014, 45, 1668-1682. [CrossRef]

31. Braekers, K.; Ramaekers, K.; Nieuwenhuyse, I.V. The vehicle routing problem: State of the art classification and review. Comput. Ind. Eng. 2016, 99, 300-313. [CrossRef]

32. Buhrkal, K.; Larsen, A.; Ropke, S. The Waste Collection Vehicle Routing Problem with Time Windows in a City Logistics Context. Procedia Soc. Behav. Sci. 2012, 39, 241-254. [CrossRef]

33. Yassen, E.T.; Ayob, M.; Nazri, M.Z.A.; Sabar, N.R. An adaptive hybrid algorithm for vehicle routing problems with time windows. Comput. Ind. Eng. 2017, 113, 382-391. [CrossRef]

34. Luo, Z.; Qin, H.; Zhang, D.; Lim, A. Adaptive large neighborhood search heuristics for the vehicle routing problem with stochastic demands and weight-related cost. Transp. Res. Part E Logist. Transp. Rev. 2016, 85, 15-29. [CrossRef]

35. Nucamendi-Guillén, S.; Angel-Bello, F.; Martínez-Salazar, I.; Cordero-Franco, A.E. The cumulative capacitated vehicle routing problem: New formulations and iterated greedy algorithms. Expert Syst. Appl. 2018, 113, 315-327. [CrossRef]

36. Tohidifard, M.; Tavakkoli-Moghaddam, R.; Navazi, F.; Partovi, M. A Multi-Depot Home Care Routing Problem with Time Windows and Fuzzy Demands Solving by Particle Swarm Optimization and Genetic Algorithm. IFAC PapersOnLine 2018, 51, 358-363. [CrossRef]

37. Xu, Y.; Qu, R.; Li, R. A simulated annealing based genetic local search algorithm for multi-Objective multicastrouting problems. Ann. Oper. Res. 2013, 206, 527-555. [CrossRef]

38. Tirkolaee, E.B.; Goli, A.; Hematian, M.; Sangaiah, A.H.; Han, T. Multi-objective multi-mode resource constrained project scheduling problem using Pareto-based algorithms. Computing 2019, 101, 547-570. [CrossRef]

39. Jacobsen, R.; Buysse, J.; Gellynck, X. Cost comparison between private and public collection of residual household waste: Multiple case studies in the Flemish region of Belgium. Waste Manag. 2013, 33, 3-11. [CrossRef] 
40. Hemmelmayr, V.; Doerner, K.F.; Hartl, R.F.; Rath, S. A heuristic solution method for node routing based solid waste collection problems. J. Heuristics 2013, 19, 129-156. [CrossRef]

41. Schneider, M.; Stenger, A.; Hof, J. An adaptive VNS algorithm for vehicle routing problems with intermediate stops. Or Spectr. 2015, 37, 353-387. [CrossRef]

42. Groot, J.; Bing, X.; Bos-Brouwers, H.; Bloemhof-Ruwaard, J. A comprehensive waste collection cost model applied to post-consumer plastic packaging waste. Resour. Conserv. Recycl. 2014, 85, 79-87. [CrossRef]

43. Xiao, Y.; Zhao, Q.; Kaku, I.; Xu, Y. Development of a fuel consumption optimization model for the capacitated vehicle routing problem. Comput. Oper. Res. 2012, 39, 1419-1431. [CrossRef]

44. Shen, L.; Tao, F.; Wang, S. Multi-Depot Open Vehicle Routing Problem with Time Windows Based on Carbon Trading. Int. J. Environ. Res. Public Health. 2018, 15, 2025. [CrossRef]

45. Jiang, R.; Guan, Y. Data-driven chance constrained stochastic program. Math. Program. 2016, 158, $291-327$. [CrossRef]

46. Heidari, R.; Yazdanparast, R.; Jabbarzadeh, A. Sustainable design of a municipal solid waste management system considering waste separators: A real-world application. Sustain. Cities Soc. 2019, 47, 101457. [CrossRef]

47. Coelho, L.C.; Laporte, G. Optimal joint replenishment, delivery and inventory management policies for perishable products. Comput. Oper. Res. 2014, 47, 42-52. [CrossRef]

48. Liu, C.; Kou, G.; Peng, Y.; Alsaadi, F. Location-routing problem for relief distribution in the early post-earthquake stage from the perspective of fairness. Sustainability 2019, 11, 3420. [CrossRef]

49. Barreto, S.; Ferreira, C.; Paixao, J.; Sousa Santos, B. Using clustering analysis location-routing in a capacitated problem. Eur. J. Oper. Res. 2007, 179, 968-977. [CrossRef]

50. Zhang, S.; Ma, H.; Lei, Y.; Fu, J. Optimization of Municipal Solid Waste Collection and Transportation Routes Considering Residents' Satisfaction. J. Syst. Manag. 2019, 28, 545-551.

51. Li, L.; Qin, G.; Yang, Y. Optimization of Integrated Inventory Routing Problem for Cold Chain Logistics Considering Carbon Footprint and Carbon Regulations. Sustainability 2019, 11, 4628. [CrossRef]

52. Qin, G.; Tao, F.; Li, L. A Vehicle Routing Optimization Problem for Cold Chain Logistics Considering Customer Satisfaction and Carbon Emissions. Int. J. Environ. Res. Public Health 2019, 16, 576. [CrossRef] [PubMed]

53. Huang, M.; Ren, L.; Wang, X. Fourth party logistics routing optimization problem with stochastic transportation time and cost. J. Syst. Eng. 2019, 34, 82-90.

54. Hannan, M.A.; Akhtar, M.; Begum, R.A.; Basri, H.; Hussain, A.; Scavino, E. Capacitated vehicle-routing problem model for scheduled solid waste collection and route optimization using PSO algorithm. Waste Manag. 2018, 71, 31-41. [CrossRef] [PubMed]

55. Ran, L.; Wu, D.; Jiao, Z.; Wang, S.; Yuan, S. Distributionally robust chance-constrained vehicle scheduling with uncertain demand. Syst. Eng. Theory Pract. 2018, 38, 1792-1801. 